\title{
Trajectories of Autonomy Development Across the Adolescent Transition in Children With Spina Bifida
}

\author{
Deborah Friedman \\ Massachusetts General Hospital \\ Christian DeLucia \\ Nova Southeastern University
}

\author{
Grayson N. Holmbeck \\ Loyola University Chicago \\ Barbara Jandasek \\ Warren Alpert Medical School of Brown University
}

\author{
Kathy Zebracki \\ Shriners Hospital for Children, Chicago
}

\begin{abstract}
Objective: The current study investigated individual growth in autonomy development across the adolescent transition, comparing the trajectories of children with and without spina bifida. Method: Individual growth curve modeling procedures were utilized to describe the developmental course of autonomy across four waves of data collection, from ages 9 to 15 , and to test whether illness status [spina bifida vs. matched comparison group $(N=68$ for both groups at Time 1)] would significantly predict individual variability in autonomy development. Potential moderators [child gender, SES, and Peabody Picture Vocabulary Test (PPVT) score] of the association between illness status and autonomy development were also examined. Results: Children with spina bifida demonstrated distinct developmental trajectories, though the nature of the group differences varied by type of autonomy development (emotional vs. behavioral), context (i.e. school vs. family), and reporter. Significant interactions with PPVT score and child gender were found. Conclusion: Overall, children with spina bifida show considerable developmental resiliency, but may lag behind their peers in specific areas of autonomy. Boys with spina bifida, and children with spina bifida who have lower than average levels of verbal intelligence, appear to be at greater risk for exhibiting delays in autonomy development.
\end{abstract}

Keywords: spina bifida, autonomy, growth curve, adolescence

Autonomy is considered a major task of normative development during the adolescent developmental period, one that is critical to the transition into adulthood (Lerner \& Galambos, 1998; Silver-

Deborah Friedman, Child and Adolescent Psychiatry, Massachusetts General Hospital; Grayson N. Holmbeck, Loyola University Chicago; Christian DeLucia, Nova Southeastern University; Barbara Jandasek, Bradley Hasbro Children's Research Center, Warren Alpert Medical School of Brown University; Kathy Zebracki, Shriners Hospital for Children, Chicago.

Completion of this manuscript was supported in part by research grants from the March of Dimes Birth Defects Foundation (12-FY01-0098) and the National Institute of Child Health and Human Development (RO1 HD048629). The authors wish to thank Ann Walsh Johnson, Joy Ito, Pat McGovern, Pat Braun, Caroline Anderson, David McLone, John Lubicky, the Illinois Spina Bifida Association, the staff of the spina bifida clinics at Children's Memorial Hospital, Shriner's Hospital-Chicago, and Loyola University of Chicago Medical Center. We also thank numerous undergraduate and graduate research assistants for help with data collection and data entry. Most importantly, we gratefully acknowledge the contributions to this study by the parents, children, teachers, and health professionals who participated over many years.

All correspondence concerning this manuscript should be addressed to Deborah Friedman, PhD, Yawkey Center for Outpatient Care, Yawkey 6A, 55 Fruit Street, Boston, Massachusetts, 02114. E-mail: dfriedman@partners.org berg \& Gondoli, 1996; Williams, Holmbeck, \& Neff Greenley, 2002). The negotiation of this developmental task has been identified as one of the most important relational transformations to occur within the family during adolescence (Hill \& Holmbeck, 1986). The development of autonomy was once regarded as the process of striving to gain freedom from one's parents, but autonomy development is now understood as an interpersonal process by which the adolescent begins to develop a greater capacity for independent behavior in the context of continued family connections (Grotevant \& Cooper, 1985; Hill \& Holmbeck, 1986; Steinberg \& Morris, 2001).

Research on autonomy development has included multiple definitions of this construct. More recently, the construct of autonomy has been disaggregated into three separate theoretically derived, first-order constructs: cognitive autonomy, emotional autonomy, and behavioral autonomy (Hill \& Holmbeck, 1986; Silverberg \& Gondoli, 1996). Cognitive autonomy has been primarily discussed within the context of models of social-cognitive development, and involves multiple-perspective taking and inferential social reasoning (Hill \& Holmbeck, 1986). Behavioral autonomy has been defined in several ways, including self-reliant behavior, intrinsically motivated behavior, and the ability to make independent decisions (Harter, 1980; Silverberg \& Gondoli, 1996), while emotional autonomy has been described as part of the separationindividuation process, or the process by which "adolescents relin- 
quish childhood dependencies on, and conceptions of, their parents" (Lamborn \& Steinberg, 1993, p. 483). The present study will focus on the development of emotional and behavioral autonomy. The evolution that takes place within family relationships over the course of adolescence has received considerable attention (Collins, 1990; Collins, Laursen, Mortensen, Luebker, \& Ferreira, 1997; Hill \& Holmbeck, 1986; Holmbeck, 1996; Steinberg \& Morris, 2001), though research on adolescent autonomy has focused almost exclusively on populations of typically developing children. In particular, considerably less attention has been paid to the development of autonomy across childhood and adolescence for youth with chronic illnesses, despite the salience of this construct for this population and the fact that this issue has often been cited as deserving increased attention (Blum, Resnick, Nelson, \& St. Germaine, 1991; Dashiff \& Bartolucci, 2002; Monsen, 1992). The task of autonomy development may be quite challenging for the adolescent with a chronic illness, particularly if the adolescent is physically disabled.

During a time when children are typically expected to establish a certain level of independence from their parents, continued dependency on adults may be necessary for an adolescent who is chronically ill. For example, adolescents who have a chronic illness will likely need continued medical care, help with the self-management of their illness (such as a reminder from their parents to take medication), and emotional support (Fritz \& McQuaid, 2000). Depending on the severity of the illness, the accomplishment of autonomy development may not be taken for granted because the extent to which the adolescent will be able to function independently as an adult may be less clear. In addition, typical adolescent-parent negotiations regarding issues of autonomy may extend to illness-related issues as adolescents develop the capacity to take more responsibility for managing their medical regimens and self-care (Shaw, 2001). Indeed, behavioral autonomy is believed to be an important condition for the development of independent illness-related self-care behaviors (Drotar \& Ievers, 1994; Hanna, DiMeglio, \& Fortenberry, 2005; Monsen, 1992; Palmer et al., 2004). Despite universal acknowledgement of the importance of autonomy development in children with chronic illness, few studies have examined autonomy development in such populations (Howe, Feinstein, Reiss, Molock, \& Berger, 1993).

The current study was part of a larger longitudinal investigation examining the transition to adolescence for children with and without spina bifida. The purpose of this study was to extend previous research on autonomy development in two ways. First, though autonomy is considered to be a developmental competency that is achieved over the course of childhood and adolescence, few studies have examined autonomy longitudinally, as a continuous and unfolding process over time. To address this issue, the present study tested a model in which individual growth in autonomy development across the transition into adolescence was examined using hierarchical linear modeling analyses. Second, the current study attempted to extend the current literature by comparing the developmental trajectories of adolescents with and without a chronic illness known as spina bifida.

Spina bifida is one of the most common birth defects, occurring in approximately 1 in every 1,000 live births in the United States (Blum et al., 1991; Charney, 1992; McLone \& Ito, 1998). Spina bifida originates in the first month of fetal development, in which the spinal column fails to develop fully, resulting in exposure of a portion of the spinal cord. The term spina bifida refers to a separation in the bones of the spinal column. Associated physical problems may include urinary, orthopedic, and neurologic difficulties. These physical problems are apparent during infancy and childhood and continue through adolescence and into adulthood. Myelomeningocele is a type of spina bifida in which the spinal cord protrudes through the opening in the spinal column, and it is associated with the most severe physical problems. Lipomeningocele is a milder form of spina bifida in which a lipoma, or fatty tumor, covers the spine (Charney, 1992). For the purposes of this study, we will use the term spina bifida to describe the illness of participants in our sample, of which $82 \%$ were categorized as myelomeningocele, $12 \%$ were described as lipomeningocele, and $6 \%$ were categorized as "other" based on medical chart data.

Descriptive studies of children with spina bifida suggest that they are faced with a number of unique social challenges that make healthy adjustment more difficult (Blum et al., 1991; Dorner, 1976). Blum and colleagues (1991) found that many adolescents with spina bifida were highly dependent on their parents for personal care. Although friends were viewed as important, adolescents with spina bifida reported a low level of contact with peers outside of school. As with other populations of children with chronic illness, children with spina bifida have been found to be at increased risk for psychosocial adjustment problems (Appleton et al., 1994, 1997).

In a recent study, based on the same sample examined in the present study, comparisons between children with spina bifida and their age-matched healthy peers, at ages 8 to 9 (Time 1 of the longitudinal study), revealed differences between the two groups across multiple dimensions of psychosocial adjustment. While no group differences were found for some of the major psychological variables such as externalizing symptoms, affective functioning, or global self-worth, there were many differences between the two groups on variables related to autonomy development. Children with spina bifida tended to be more passive, more dependent on adults for guidance, less likely to make independent decisions, and displayed less intrinsic motivation in school. Moreover, these findings were consistent across reporters and contexts, including child report, parent report, teacher report, and observations during family interactions (Holmbeck et al., 2003). These findings suggest that autonomy may be at the heart of the psychosocial difficulties that youth with spina bifida face relative to their peers, and indicated that this developmental process deserved further attention within this population.

The current study investigated potential differences between children with and without spina bifida by using individual growth curve modeling procedures to compare individual trajectories of autonomy development in the two samples across the transition into adolescence. It was hypothesized that illness status (group with spina bifida vs. comparison group) would be a significant predictor of individual variability in autonomy development. Specifically, it was hypothesized that children with spina bifida would lag behind their peers in autonomy development, starting at a lower level of autonomy and additionally demonstrating a less rapid growth trajectory as they transition into adolescence. In other words, it was expected that children with spina bifida would start out behind in their level of autonomy and never catch up, with the distance between them and their peers growing as they enter the developmental stage of adolescence. 
Autonomy development was assessed using multiple sources and multiple methods across the contexts of home and school, and across four separate time points from age 8 through age 15 . Given that there is a dearth both of research examining the child's report of their own psychosocial adjustment (Lavigne \& Faier-Routman, 1992) and research examining paternal perspectives on child adjustment (Phares, Fields, Kamboukos, \& Lopez, 2005; Quittner \& DiGirolamo, 1998), the current study used child-, mother-, father-, and teacher-report questionnaires, as well as observational data.

Several potentially important moderators of the process of autonomy development were also examined. Previous research suggests that socioeconomic status (SES) and gender may impact adjustment outcomes for children with chronic illness (Appleton et al., 1997; Frank, Blount, \& Brown, 1997). Appleton and colleagues found that girls with spina bifida were at greater risk than boys with spina bifida for depressive symptoms and low self-worth (Appleton et al., 1997). In a previous study with the present sample, low SES was found to add cumulative risk for adjustment difficulties in children with spina bifida (Holmbeck et. al., 2003). In addition, children with spina bifida tend to have a different neurological profile than their age-matched peers. The intelligence scores of children with spina bifida tend to be below average, but within the normal range on most other tests (Wills, 1993; Wills, Holmbeck, Dillon, \& McLone, 1990). As expected, there was a significant difference found between the samples on a measure of receptive language (Peabody Picture Vocabulary Test - Revised; PPVT-R; Dunn \& Dunn, 1981): $M=92.49$ ( $S D=18.49)$ for the group with spina bifida and $M=108.97(S D=15.06)$ for the comparison group. Therefore, PPVT-R scores were also included in the analyses and examined as a potential moderator of the relationship between illness status and the development of autonomy. Thus, we examined, in an exploratory manner, whether interactions between illness status (group with spina bifida vs. comparison group) and three variables-gender, SES, and intellectual functioning - were associated with trajectories of autonomy development. A significant interaction effect would indicate that these variables were moderators of the association between illness status and autonomy development (Holmbeck, 1997).

\section{Method}

\section{Participants}

Participants in this study were part of a larger longitudinal investigation of psychosocial adjustment and family relationships during the transition to adolescence in children with spina bifida, conducted at Loyola University Chicago, and funded by the March of Dimes (Friedman, Holmbeck, Jandasek, Zukerman, \& Abad, 2004; Holmbeck et al., 2003). During the first data collection period (Time 1), 68 families with a child 8 or 9 years old who has spina bifida were interviewed. The comparison sample consisted of 68 families with an able-bodied child. Participants from the group with spina bifida and comparison group were matched on the following demographic variables: child age, child gender, child ethnicity, birth order, family structure (intact or not intact), maternal and paternal income, family SES, and age of both parents. Significant differences were not found between the two groups on any of these variables, indicating that the groups were successfully matched (see Table 1).

Children with spina bifida were recruited from the following sources: a children's hospital, a children's hospital that cares exclusively for children with physical disabilities, a universitybased medical center, and a statewide spina bifida association. A letter was sent to all parents of children within the 8-9 year-old range. Sixty-eight families of children with spina bifida comprised the final group of participants. Within this group of participants, location of spinal lesion level (as obtained from the medical chart) varied with $32 \%$ sacral, $54 \%$ lumbosacral or lumbar, and $13 \%$ thoracic. Maternal report indicated that $63 \%$ ambulated with the assistance of braces, $18 \%$ used a wheelchair, and $19 \%$ required no ambulation assistance, and that $71 \%$ of the sample had a shunt placed (29\% did not have a shunt). The average number of shunt

Table 1

Demographics: Comparisons Across Samples

\begin{tabular}{lccc}
\hline Demographic characteristics & Spina bifida & Comparison group & Statistical test \\
\hline Child age in years, $M(S D)$ & $8.34(0.48)$ & $8.49(0.50)$ & $t(134)=-1.75$ \\
Maternal age in years, $M(S D)$ & $37.74(5.19)$ & $37.74(4.84)$ & $t(134)=0.00$ \\
Paternal age in years, $M(S D)$ & $41.02(5.45)$ & $40.63(6.50)$ & $t(105)=0.33$ \\
Child gender & & & \\
$\quad$ Male, \% $(n)$ & $54.41(37)$ & $54.41(37)$ & $\chi^{2}(1)=0.00$ \\
Female, \%(n) & $45.59(31)$ & $45.59(31)$ & \\
Child ethnicity & & & \\
$\quad$ White, \% $(n)$ & $82.35(56)$ & $91.18(62)$ & $\chi^{2}(1)=2.30$ \\
Other, \% $(n)$ & $17.65(12)$ & $2.06(1.29)$ & $t(129)=0.27$ \\
Child birth order, $M(S D)$ & $2.12(1.38)$ & $69.12(47)$ & \\
Marital status & & $30.88(21)$ & $\chi^{2}(1)=2.51$ \\
$\quad$ Two-parent intact, $\%(n)$ & $80.88(55)$ & $5.73(2.45)$ & $t(130)=0.05$ \\
$\quad$ Nonintact, \% $(n)$ & $19.12(13)$ & $6.35(2.22)$ & $t(105)=-0.24$ \\
Maternal income, $M(S D)$ & $5.75(2.57)$ & $46.46(10.89)$ & $t(131)=-1.80$ \\
Paternal income, $M(S D)$ & $6.24(2.50)$ & & \\
Hollingshead SES, $M(S D)$ & $43.12(10.57)$ & &
\end{tabular}

Note. $n=68$ for each sample. Family income is rated on a scale from 1 to 11 on which $1<\$ 10,000,5=$ $\$ 40,000-49,000,10=\$ 90,000-99,999$, and $11>\$ 100,000$. The Hollingshead (1975) Four Factor Index of socioeconomic status (SES) is based on a composite of maternal education, paternal education, maternal occupational status, and paternal occupational status. All statistics were nonsignificant. 
surgeries among those with shunts was $2.50(S D=2.91)$. A comparison of participating children with children from families who declined to participate revealed no differences with respect to lesion level, $\chi^{2}(2)=.62, p>.05$, or type of spina bifida (myelomeningocele vs. lipomeningocele), $\chi^{2}(1)=1.63, p>.05$.

Participants in the comparison group were recruited by contacting schools where the participating children with spina bifida were enrolled. It was unnecessary to contact all schools to obtain a comparison group of the same size as the group with spina bifida. Parents who desired to participate returned a form indicating their consent. Parents who returned consent forms were then contacted by phone. Sixty-eight families of able-bodied children comprised the final comparison group at Time 1 (see Holmbeck et al., 2003 for a more detailed description of recruitment and matching procedures).

Data collection for the larger longitudinal study occurred every 2 years. The present study examined autonomy development through the first four waves of data collection. At Time 1, children in the sample were 8 or 9 years old, and at Time 4 , the children in the sample were 14 or 15 years old. The total sample completing both Time 1 and Time 2 interviews consisted of 67 families of children with spina bifida and 66 families in the comparison group, with a retention rate of $99 \%$ for the group with spina bifida and 97\% for the comparison group. At Time 3, 64 families of children with spina bifida participated (94\%) and 66 in the comparison group participated (97\%). At Time 4, 60 families of children with spina bifida participated (88\%) and 65 families in the comparison group participated $(96 \%)$.

\section{Measures}

Demographics. At each session, parents responded to a series of questions regarding demographic information, through which the variables of child gender and family SES were obtained. Both child gender and illness status were examined as predictors in the growth curve models. Spina bifida diagnostic status was obtained at baseline $(0=$ comparison youth $; 1=$ youth with spina bifida $)$. A continuous measure of child age in years was obtained during each wave of data collection using the child's birth date and date of interview. This variable was used as the time variable in the growth curve models. The age variable was scaled such that the zero point was equal to the value of age 9, the average age at study entry.

Autonomy development. Four indices of autonomy development were utilized in this study to capture separate conceptualizations of autonomy across multiple contexts and reporters. Three of these were measures of behavioral autonomy: (a) the degree to which the child makes independent decisions within the family, (b) observed dependent vs. independent behaviors in a family interaction task, and (c) intrinsic motivation as reported by the teacher and as demonstrated in the classroom. The study also included a measure of emotional autonomy or the degree to which the child has emotionally individuated from his/her parents.

The degree of independent decision making within the family was measured with the Decision-Making Questionnaire (Steinberg, 1987). Mothers, fathers, and children were asked to each rate their perception of who in the family makes decisions about the child's behavior. Each respondent rated 15 issues, such as when the child has to do homework or which friends the child spends time with, with the following choices: (a) parents tell child what to do, (b) parents and child discuss the issue, but parents have the final say, (c) parents and child discuss the issue, but child has the final say, and (d) the child decides. This questionnaire measure was scored in the direction of greater behavioral autonomy for the child. Within the group of children with spina bifida, across the four data collection time points, $\alpha$ values ranged from .77 to $.90(M=.84)$ for father report, from .80 to $.90(M=.86)$ for mother report, and from .66 to $.81(M=.75)$ for child report of individual decision-making. Within the comparison group, across the four time points, $\alpha$ values ranged from .66 to $.85(M=.80)$ for father report, from .57 to .81 $(M=.70)$ for mother report, and from .78 to $.88(M=.83)$ for child report of individual decision making.

Observed dependent behavior was coded using a global coding system developed by Johnson and Holmbeck (1994; Holmbeck et al., 2002), which was based on a methodology devised by Smetana, Yau, Restrepo, \& Braeges (1991). This behavioral coding system assesses both parental intrusiveness, which was not examined in the present study, and child independent/dependent behaviors, which was one of the outcome measures examined. Trained undergraduate and graduate-level coders viewed family interaction tasks and then provided 5-point Likert scale ratings (ranging from "almost never" to "almost always") assessing the child's independent/dependent behaviors. Any score greater than 1 indexed the presence of excessive child dependent behavior. The child dependent behavior scale included five codes: (a) "child engages in nonverbal exploratory behavior" (reverse-scored), (b) "child expresses individual views/opinions" (reverse-scored), (c) "child is needy," (d) "child seeks an excessive amount of physical contact," and (e) "child acts like a baby." All items in the coding system were rated by two coders for two interaction tasks across all families. Ratings were then combined across the two raters and two tasks to create one code for each variable on each family. Alphas for the observed dependent behavior scale averaged .64 and .72 across all four time points for the comparison group and the group with spina bifida, respectively. Interrater reliability averaged .73 across all four time points for the comparison group and .74 across all four time points for the group with spina bifida.

Intrinsic motivation was assessed using a teacher-report of Harter's (1980) 10-item 4-point scale of Intrinsic Versus Extrinsic Orientation in the Classroom - Revised. This measure assessed child motivation across five dimensions: Challenge (preference for challenge vs. preference for easy work); Curiosity (doing work to satisfy one's own interest vs. doing schoolwork in order to satisfy one's teacher or obtain grades); Independent Mastery (preference for doing own work and problem solving vs. reliance on teacher for help and guidance to figure out problems and assignments); Independent Judgment (independent decision making vs. dependence on teacher's opinion); and Internal Criteria for Success/ Failure (child knows when he/she has succeeded or failed vs. child is dependent on external sources of evaluation). The total intrinsic motivation score was used (i.e. the average item score across all items). Alphas for all four waves of data collection for the intrinsic motivation scale ranged from .79 to $.84(M=.82)$ for the group with spina bifida, and from .72 to $.87(M=.81)$ for the comparison group.

Emotional autonomy was assessed with the child report on three subscales (Parental Deidealization, Nondependency on Parents, and Individuation) of the Emotional Autonomy Scale (EA; Stein- 
berg \& Silverberg, 1986). Children were asked to rate how much they agreed on a 4-point Likert scale with 14 statements (e.g., "Even when my mother and I disagree, my mother is always right," "I try to have the same opinions as my mother," "I go to my mother for help before trying to solve a problem myself."; all reverse scored). Each child participant completed this questionnaire twice at each wave of data collection, once regarding their relationship with their mother and once regarding their relationship with their father. For child report of emotional autonomy from mothers, Time 1 through Time 4 alpha values ranged from .62 to $.80(M=.70)$ within the group with spina bifida, and from .69 to $.82(M=.78)$ within the comparison group. For child report of emotional autonomy from fathers, Time 1 through Time 4 alpha values ranged from .54 to $.83(M=.72)$ within the group with spina bifida, and from .69 to $.82(M=.75)$ within the comparison group.

Intellectual functioning. The PPVT-R (Dunn \& Dunn, 1981), a measure of receptive language, was used here as an estimate of intellectual functioning at Time 1 . While a significant difference was found between the samples on this measure $[M=92.49$ $(S D=18.49)$ for the sample with spina bifida and $M=108.97$ ( $S D=15.06)$ for the comparison sample], the two groups were not matched on this variable, because a lower average verbal IQ was viewed as part of the symptom presentation for children with spina bifida. The PPVT-R is considered to have excellent reliability and validity (Sattler, 2002).

\section{Procedure}

Data at each wave of the study were collected during a 3-hour visit to the family's home. Data collection was conducted by trained graduate and undergraduate psychology students. Each family was paid $\$ 50$ for their participation at Time $1, \$ 75$ for their participation at Time 2 and Time 3, and $\$ 100$ for their participation at Time 4. During both sessions, a brief overview of study goals and confidentiality issues were first reviewed with the family, and then parents were asked to sign a consent form for themselves and their child. Children were also asked to sign an assent form for their own participation. The family then participated in the completion of questionnaire packets and a series of videotaped family interaction tasks.

Two of the videotaped tasks (an unfamiliar board game and a conflict task) were coded based on a family interaction coding system to assess child independent/dependent behaviors (Holmbeck et al., 2002; Johnson \& Holmbeck, 1994). For the unfamiliar board game task, families were asked to play a game that they had not seen before and to generate their own rules. The conflict task was based on a procedure used by Smetana et al. (1991). During the questionnaire portion of the home visit, both the parents and the child separately completed a questionnaire assessing parentchild conflict, a short form of the Issues Checklist (Robin \& Foster, 1989). Prior to the beginning of the interaction tasks, research assistants tabulated weighted conflict scores (i.e. frequency $\times$ intensity) for each issue endorsed and then summed these weighted scores to get a total family score for each issue. The five issues that received the highest total weighted conflict score were presented to the family for discussion during the conflict task. Family members were asked to select three of the five issues and to discuss them for a total of $10 \mathrm{~min}$.
Results

\section{Preliminary Statistical Considerations}

Four unique outcome measures were assessed (independent decision making, intrinsic motivation, observed dependent behavior, and emotional autonomy). Because multiple reporters were assessed on two of the outcomes (i.e., three reporters for independent decision making and two versions of the emotional autonomy measure), a total of seven "sets" of statistical analyses are discussed. Given our interest in modeling developmental trajectories of various youth characteristics, individual growth curve models were estimated using the Mixed Procedure in SAS statistical software (see Singer, 1998). In this modeling framework both within-person (intraindividual) and between-person (interindividual) change across the transition to adolescence can be explored.

Our analytical approach was modeled closely after that described and illustrated by DeLucia and Pitts (2006). Moreover, given that a similar tutorial paper was recently published in $R e$ habilitation Psychology (Kwok et al., 2008), we link our analytical framework with models presented in that paper as well. In short, we first estimated unconditional growth models to determine the functional form of growth (e.g., linear vs. quadratic). Relative model fit was assessed by comparing the $-2 \log$ likelihood statistics of competing (i.e., nested) models (see, Snijders \& Bosker, 1999). Full maximum likelihood estimation was used for all models. In the instance of linear growth models, these models were similar in form to those presented in equations 4 through 6 by Kwok et al. (2008). Once the best-fitting growth model was selected, seven time-invariant covariates were entered as predictors of the growth parameters (e.g., trajectory intercepts): (a) illness status; (b) participant gender; (c) participant SES; (d) participant standard score on the PPVT; and (e) the 3 two-way interactions involving illness status (e.g., illness status by gender) Nonsignificant interactions were trimmed from final models; all lower-order effects were retained regardless of significance. As such, the final model for each analysis included all four (lowerorder) predictors of the trajectory parameters as well as any retained significant interaction. These models were similar in form to those presented in equations 7 through 9 by Kwok et al. (2008). Our models, however, included a minimum of four predictors of the various growth parameters, which would result in an expansion of Kwok et al's equations 7 and 8 to include a minimum of four predictors. (Consequently, Kwok et al.'s integrated model (equation 9) would be expanded as well). Significant interactions were probed and graphically displayed following the methods of Aiken and West (1991). Consistent with our primary aim of exploring differential development as a function of spina bifida status and to simplify our presentation, only significant effects involving illness status are described below.

Chronologic age, centered at age 9, was the original "time" predictor in all models. In linear models, the fixed intercept estimate is interpreted as the average predicted score on the outcome for 9-year-old youth. The fixed slope estimate is interpreted as the predicted constant rate of change in the outcome for a 1-year change in age. For quadratic models, the fixed intercept has the same interpretation as described above. The linear component, however, is interpreted as the average predicted instantaneous 
growth rate for 9-year-old youth. The quadratic component is the average rate of trajectory curvature.

\section{Modeling Growth Over Time in Autonomy Development}

Individual decision making. Growth in child, mother, and father reports of the child's individual decision making within the family was quadratic in nature. For all three reporters, growth models included both fixed and random effects for intercepts and slopes; the quadratic components were estimated as fixed effects only. For child-report models, illness status was a significant predictor of the quadratic component (est $=.02, S E=.008, p=$ .01 , see Figure 1). As shown in Figure 1, trajectory "curvature" for the spina bifida group was positive and significant (est $=.024$, $S E=.006, p<.0001)$. For the comparison group, however, trajectory curvature was nonsignificant. Trajectory intercepts (average predicted score of behavioral autonomy) evaluated at age 9 varied by illness status with youth with spina bifida reporting lower levels (est $=-.225, S E=.09, p=.01$ ). Given the differential rates of trajectory curvature, at age 15 trajectory heights were again different, but in the opposite direction, with youth with spina bifida reporting higher levels of behavioral autonomy (est $=.42, S E=.15, p=.007)$. For mother-report models, both the linear (est $=.034, S E=.016, p=.036$ ) and quadratic (est $=.01, S E=.003, p=.001$ ) components were positive and significant indicating an increase over time in behavioral autonomy.

For father-report models, illness status interacted with gender in predicting intercept variability (est $=-.395, S E=.123, p=.002$, see Figure 2). For comparison youth, intercepts did not vary significantly as a function of youth gender. For youth with spina

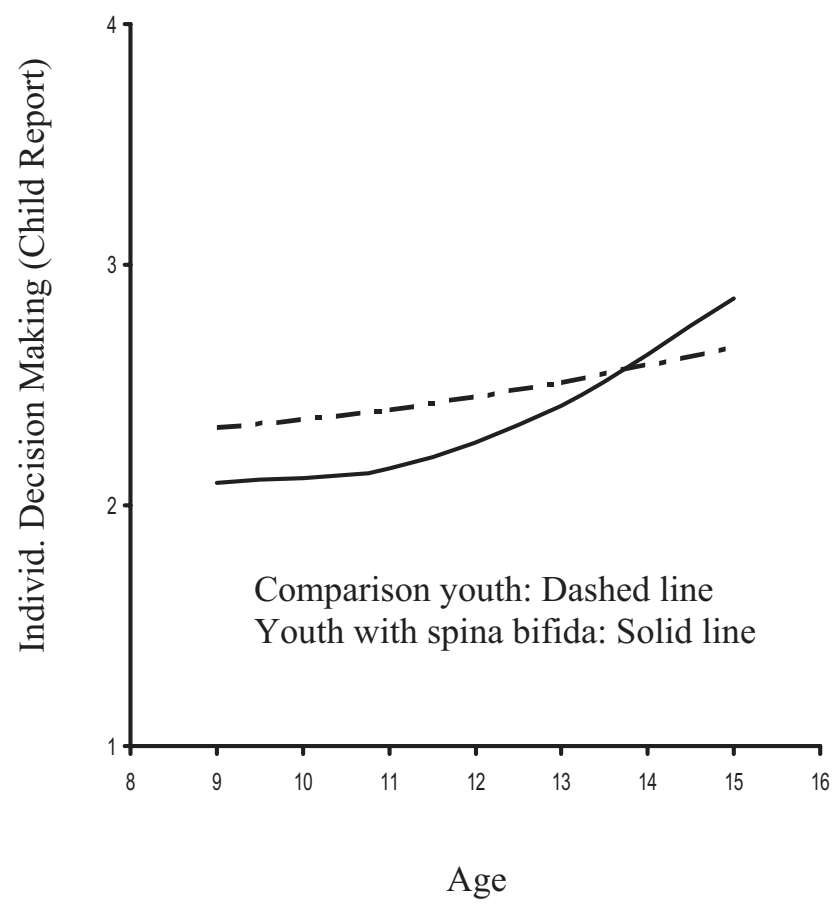

Figure 1. Illness status effect on trajectory curvature of child report of individual (Individ) decision making. bifida, girls reported higher intercepts (est $=.27, S E=.09, p=$ .004).

Observed child dependent behavior. The form of growth for observed child dependent behavior was quadratic in nature. Although fixed effects were included for intercepts, linear components, and quadratic components, only the intercept was modeled as a random effect. The linear component was negative and significant (est $=-.131, S E=.015, p<.0001)$; whereas trajectory curvature was positive and significant (est $=.016, S E=.002, p<$ .0001). Illness status was a significant predictor of intercept variability; youth with spina bifida were observed as having higher levels of dependent behavior at age 9 (est $=.25, S E=.05, p<$ $.0001)$, and this significant difference remained constant across time (see Figure 3).

Intrinsic motivation. Teacher reported growth over time in intrinsic motivation was linear in nature and included both fixed and random effects for trajectory intercepts and slopes. A statistically significant illness status by PPVT interaction was observed in predicting variability in linear slopes (est $=.003, S E=.001, p=$ .007). To probe this interaction we plotted growth curves by illness status at low $(-.75 S D)$, average $(M)$, and high $(+.75 S D)$ values of PPVT (see Figure 4). At low values of PPVT, there was a marginally significant illness status effect in predicting linear variability (est $=-.044, S E=.03, p=.093$ ). The positive linear trend for comparison youth was significant (est $=.072, S E=.027$, $p=.009)$; whereas the linear trend for spina bifida youth was nonsignificant (est $=.009, S E=.022, p=.677$ ). Although trajectory intercepts were not significantly different at age 9 , by age 15 , as the trajectories diverged over time, comparison youth had significantly higher levels of intrinsic motivation (est $=.44$, $S E=.12, p=.0005)$. At average values of PPVT, the trajectories were nearly parallel and as such significant between-group differences were maintained across ages. For example, at age 9, comparison youth had significantly higher levels of intrinsic motivation (est $=.26, S E=.10, p=.01)$. At higher values of PPVT, linear components did not vary significantly as a function of group (est $=.035, S E=.025, p=.1573$ ). Neither group trend was significant. It is worth noting that only at higher values of PPVT do the trajectories converge by age 15 resulting in parity between the two groups.

Emotional autonomy. Children also reported on their growth over time in emotional autonomy from both fathers and mothers. Although none of the covariates were significant predictors of growth in emotional autonomy from fathers, the average linear trajectory was positive and significant indicating significant gains in emotional autonomy from fathers over development.

Growth over time in emotional autonomy from mothers was linear in nature and included both fixed and random effects for intercepts and slopes. Illness status interacted with youth gender (est $=-.06, S E=.03, p=.05$ ) and PPVT (est $=.003, S E=$ $.0009, p=.0025)$ in predicting linear slopes. The plot of the interaction involving gender is presented in Figure 5. For the comparison group, both boys and girls gained in emotional autonomy at about the same rate, resulting in a nonsignificant simple effect of gender. In contrast, girls with spina bifida increased in emotional autonomy more dramatically than did boys (est = $.0443, S E=.022, p=.048)$.

The plot of the interaction involving PPVT is presented in Figure 6. At low, average, and high values of PPVT, both com- 

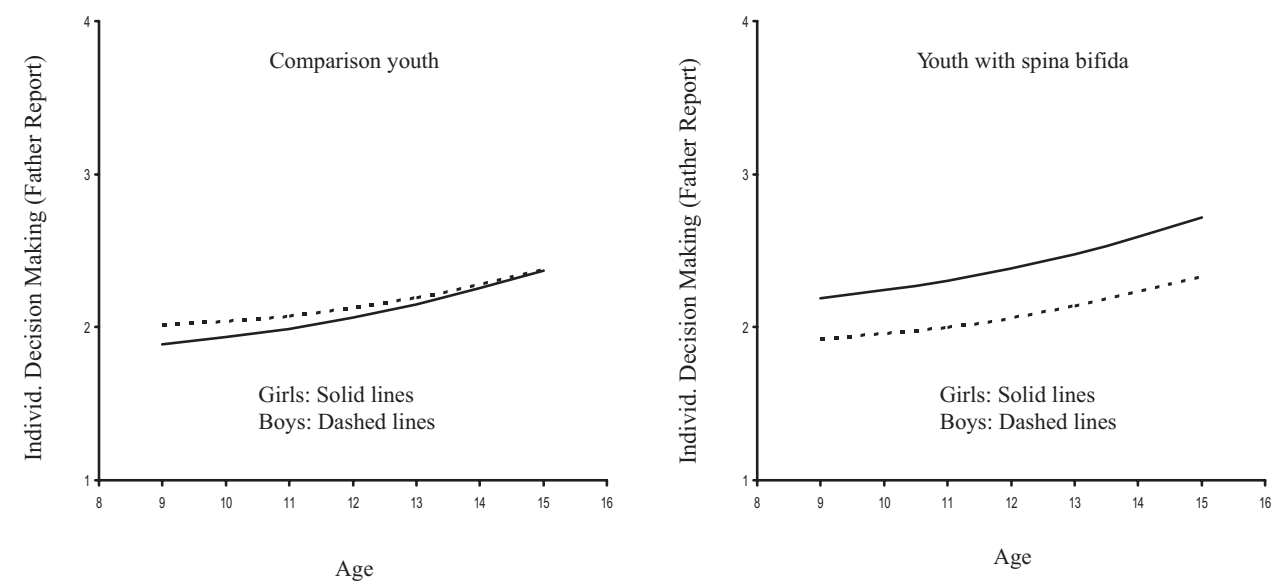

Figure 2. Illness status by gender interaction in predicting intercepts of father report of individual (Individ.) decision making.

parison and youth with spina bifida had positive and significant linear trends (e.g., for comparison youth at low levels of PPVT, est $=.11, S E=.02, p<.0001)$. An examination of Figure 6 shows that for comparison youth the linear trend loses strength from low through high values of PPVT; for youth with spina bifida, however, the pattern is reversed and the trend strengthens from low through high values of PPVT.

\section{Discussion}

The purpose of the present study was to investigate individual growth in autonomy development across the transition to adolescence comparing the developmental trajectories of children with

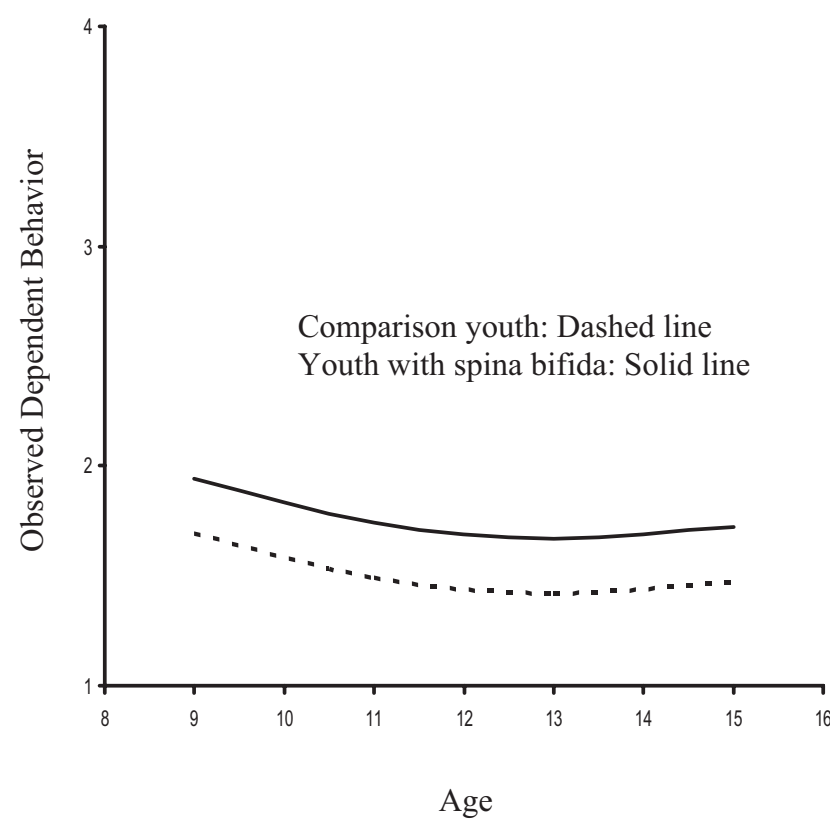

Figure 3. Illness status effect in predicting intercepts of observed child dependent behavior. and without spina bifida. Individual growth curve modeling procedures were utilized to describe the developmental course of autonomy across four waves of data collection, from ages 9 to 15 , and to test whether illness status would significantly predict individual variability in autonomy development. Potential moderators (child gender, SES, and PPVT score) of the association between illness status and autonomy development were also examined. It was predicted that children with spina bifida would lag behind their peers in autonomy development, starting at a lower level of autonomy and additionally demonstrating a less rapid growth trajectory as they transition into adolescence. The results provide a somewhat more complicated picture of autonomy development across the adolescent transition within the context of a chronic illness. Overall, for both the group of children with spina bifida and the comparison group, levels of autonomy tended to increase over time from childhood (age 9) to adolescence (age 15). This finding is consistent with previous research on autonomy development (Eccles et al, 1993; Sigafoos, Feinstein, Damond, \& Reiss, 1988; Steinberg and Silverberg, 1986). This general increase in autonomy over time was not found in two instances, however. Within the comparison group, children did not self-report significant growth in individual decision making over time, and teacher report of levels of intrinsic motivation in the classroom did not appear to increase over time for either group, except in the case of children in the comparison group who had lower than average PPVT scores. More generally, group differences between children with spina bifida and their age-matched peers in developmental trajectories were evident across measures of autonomy. The specific nature of these differences, however, varied by type of autonomy development (emotional vs. behavioral), context (i.e. school vs. family), and reporter (i.e. mother, father, child, or observational measure). In addition, interactions with background factors, such as the child's gender and PPVT score, were prevalent.

In general, children with spina bifida and their age-matched peers both show increases in independent behavior and emotional autonomy from their parents over time. As such, when the acquisition of autonomy is examined as a developmental process rather than a static snapshot, children with spina bifida appear to demonstrate considerable developmental resiliency in the face of sig- 


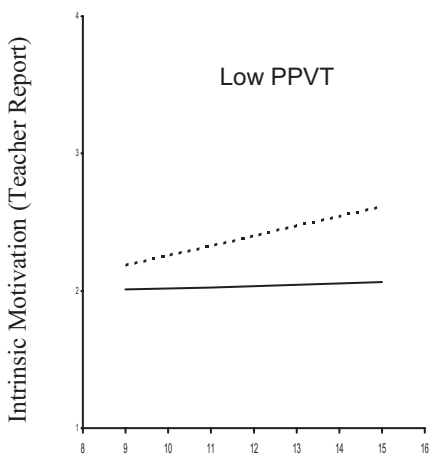

Age

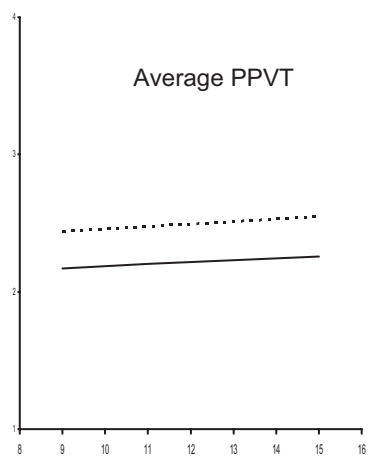

Age

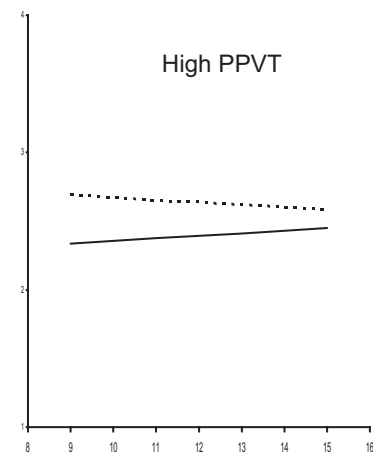

Age

Comparison youth: Dashed Lines

Youth with spina bifida: Solid Lines

Figure 4. Illness status by Peabody Picture Vocabulary Test (PPVT) interaction in predicting linear slopes of teacher report of intrinsic motivation.

nificant challenges (Blum et al., 1991; Dashiff \& Bartolucci, 2002; Monsen, 1992). In certain areas, however, children with spina bifida appear to lag behind their peers with regard to autonomy development, demonstrating the salience of this construct for this specific population (Holmbeck et al., 2003). Significant moderation in the model suggests subgroups of children with spina bifida who, in particular, may need additional help in managing the adolescent transition and attaining the developmental competency of emotional and behavioral autonomy (Lerner \& Galambos, 1998; Silverberg \& Gondoli, 1996; Steinberg \& Morris, 2001; Williams, Holmbeck, \& Neff Greenley, 2002).

As noted, results varied across measures of autonomy development. Consistent with hypotheses regarding expected group differences in trajectories of observed dependent behavior, a main effect for illness status was found such that children with spina bifida demonstrated significantly more dependent behavior at age 9. Both groups appeared to decrease in dependent behavior at a similar rate across time. Therefore, the group difference that was significant in childhood was maintained across the transition to adolescence, and at age 15 , children with spina bifida continued to demonstrate significantly more dependent behavior in observed family interactions. On the other hand, child report of development of individual decision making within the family context demonstrated a different pattern. While at age 9, children with spina bifida group reported significantly lower levels of independent decision-making behavior than the comparison group, the children in this group also reported a stronger rate of growth over time, so that by age 15, they "caught up" and even surpassed the comparison group with regard to self-reported individual decision-making behavior. This somewhat counterintuitive finding, however, was relatively inconsistent with the majority of the results, which tended to indicate that children with spina bifida demonstrated lower levels of behavioral autonomy than their peers. It is possible that children with spina bifida understood these behavioral auton-

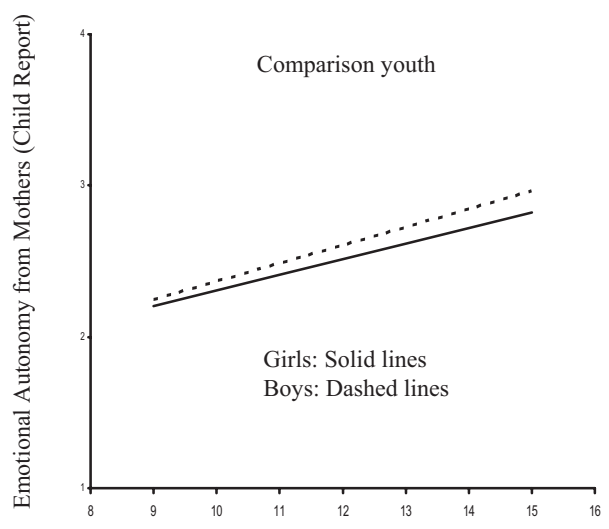

Age

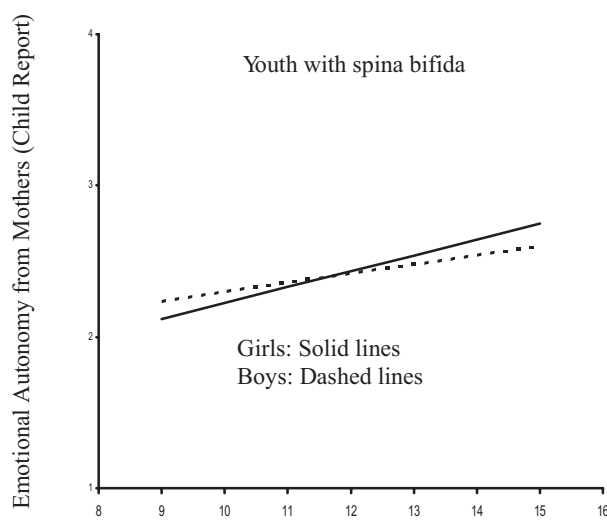

Age

Figure 5. Illness status by gender interaction in predicting linear slopes of child report of emotional autonomy from mothers. 


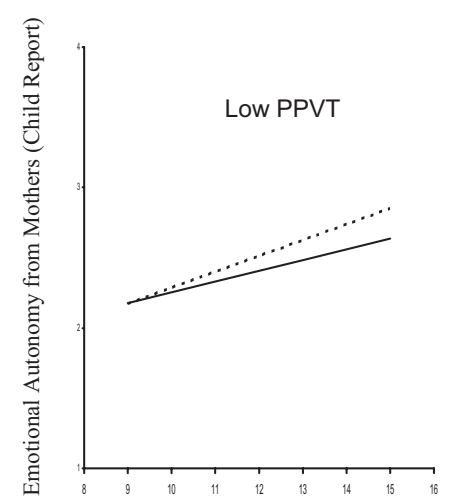

Age

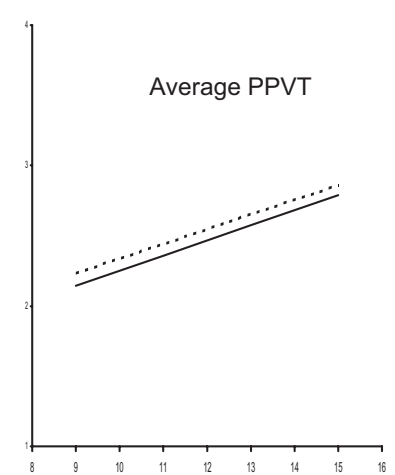

Age

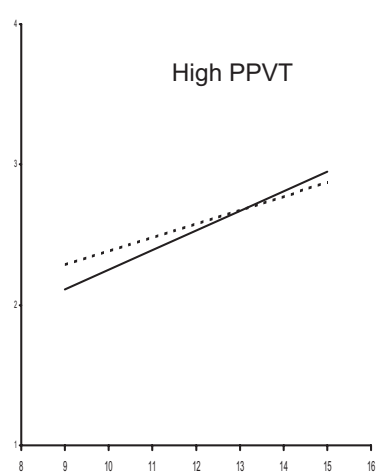

Age

Comparison youth: Dashed Lines

Youth with spina bifida: Solid Lines

Figure 6. Illness status by Peabody Picture Vocabulary Test (PPVT) interaction in predicting linear slopes of child report of emotional autonomy from mothers.

omy items differently, perhaps owing to their lower level of verbal ability.

Both child gender and PPVT were found to significantly interact with illness status in the prediction of individual variability in autonomy development. Significant gender by illness status interaction effects were found for both child report of emotional autonomy from mothers and father report of decision-making autonomy. In the model of growth in emotional autonomy from mother, both girls and boys within the comparison group gained autonomy at similar rates, but boys did not increase in emotional autonomy at the same rate as girls within the group of children with spina bifida. Similarly, in the model of growth in father report of individual decision making, trajectory intercepts did not vary significantly as a function of child gender within the comparison group. By contrast, within the group of children with spina bifida, girls showed higher levels of decision making than boys at age 9, and given a similar rate of growth over time, gender differences persisted into adolescence. In both of these cases, results suggest that boys with spina bifida are particularly at risk for exhibiting delays in autonomy development. If autonomy development parallels other aspects of typical maturation, this increased risk for boys may be partially explained by the fact that, overall, girls tend to physically and emotionally mature at a faster pace than do boys (Taylor, 1985).

An index of IQ (PPVT scores) also appeared to moderate the effect of illness status on the development of autonomy. In the group with spina bifida, children with lower than average PPVT scores exhibited a slower growth rate in emotional autonomy from mothers across the transition into adolescence. Similar group differences for children with lower levels of PPVT were found with respect to longitudinal trajectories of teacher report of intrinsic motivation within the classroom. Children in the comparison group demonstrated increases in intrinsic motivation over time, while children with spina bifida did not. At age 15, the comparison group showed significantly higher levels of intrinsic motivation. For children falling within the average PPVT score range, given the lack of linear growth in intrinsic motivation over time for both children with and without spina bifida, the comparison group maintained consistently higher levels of teacher-reported intrinsic motivation over time. Children with spina bifida who demonstrate lower than average levels of PPVT, in particular, may not demonstrate levels of intrinsic motivation that are consistent with attaining psychosocial adaptation during adolescence. Interestingly, in a recent study, teacher report of intrinsic motivation was found to be the most important factor predicting psychosocial adaptation during early adolescence for both children with and without spina bifida (Coakley, Holmbeck, \& Bryant, 2006).

The meaning of differences between children with and without spina bifida in trajectories of independent behavior can only be understood within a developmental context. Expectations for greater individual decision-making ability, more self-reliant behavior, and greater independent initiative and learning in the classroom increase with age (Holmbeck, Paikoff, \& Brooks-Gunn, 1995). Therefore, a lower level of autonomy during adolescence may indicate a significant divergence from a typical developmental path. In addition, it is during adolescence that children begin to compare themselves to their peers (Shaw, 2001), and as such, awareness of peer differences with regard to behavioral autonomy during this time may more acutely affect a child's sense of themselves and their interactions with others. Moreover, during adolescence, children with a chronic illness are typically expected to take more responsibility for self-management of their illness. Lags in the development of behavioral autonomy may delay an adolescent's capacity for independent illness-related self-care (Drotar \& Ievers, 1994; Hanna et al., 2005; Monsen, 1992; Palmer et al., 2004).

Autonomy development during adolescence may also impact adaptation during subsequent transitions. Masten and colleagues found that autonomy development was one of the most important factors relating to success in emerging adulthood. Evidence was also found for autonomy as a protective factor, predicting resilience in the transition to adulthood for young people who demon- 
strated maladaptation at the onset of this transition (Masten et al., 2004). The fact that children with spina bifida demonstrate different developmental trajectories from their peers on measures of autonomy across the transition to adolescence suggests that autonomy development is a significant area of psychosocial concern for them. Results of the current study suggest that boys with spina bifida and children with spina bifida with lower levels of verbal intelligence may be particularly at risk.

Several limitations of the current investigation are noteworthy and may point to directions for future research. First, the sample size utilized in this study was relatively small, and although the rate of attrition was low, there was some participant loss over time. Future studies would benefit from the use of a larger sample. While matching at the individual level would have been a preferable approach, due to practical concerns, the study utilized a group level rather than an individual level process to match the samples on 10 different demographic variables. There are also limitations to the generalizability of study findings. The sample was a relatively homogenous one, and as a result, the findings of this study are generalizable primarily to white, English-speaking families. Future research in this area should employ more ethnically diverse samples, with a particular focus on the recruitment of Latino families, given the high rate of spina bifida among Latino populations (Lary \& Edmonds, 1996).

Additionally, although the present investigation followed families across four time points over an 8-year period from childhood into early adolescence, the study did not cover the entire duration of adolescent development. Therefore, conclusions that can be made from this study about behavioral and emotional autonomy development pertain only to this period. Later adolescence (16 years and beyond) may be an even more salient time to examine behavioral autonomy and a time when greater variability in autonomy gains across families may be more apparent. Further research would be necessary to examine how trajectories of adolescent autonomy development may predict the transition to independent adulthood. The transition into adulthood may be particularly challenging for individuals with a chronic illness, who have the added stress of making a transition from the pediatric health care system to an adult system of care. Furthermore, at Time 1 of this study, there were already significant differences in behavioral autonomy variables between children with and without spina bifida. Therefore, it would be worthwhile to examine neurologic and psychosocial factors prior to age 9 that may affect the early development of autonomy to gain a better understanding of how group differences evolve.

Within the present study, results concerning the measure of intrinsic motivation should be interpreted with some caution. Due to the change in classroom teachers that inevitably occurred as the sample entered different grades over time, different teachers were asked to report on the intrinsic motivation of the child within the classroom at the four data collection time points. Therefore, in this case, measurement change as indexed by a change in the reporter may be confounded with the true change that we hoped to capture with these models. Also, given that children with spina bifida may have hydrocephalus-related cognitive difficulties, cognitive differences between groups may have impacted study findings for those results involving child report of autonomy. In addition, given the significance that a relatively gross measure of cognitive ability such as the PPVT appears to have on the development of autonomy, it may be important to examine the impact of more specific neuropsychological functions. Specific neuropsy- chological functions may have an impact on the autonomy development of children with spina bifida, as children with spina bifida evidence a different neuropsychological profile than their healthy peers (Wills, 1993; Wills et al., 1990).

Very little is known about the determinants of behavioral autonomy development (Silverberg \& Gondoli, 1996). Therefore, future research could examine how specific parenting or family processes or how social relationships with peers may facilitate the successful negotiation of this developmental task. Moreover, illness-specific predictors of autonomy may be particularly salient for children with spina bifida. For example, child and parental beliefs about the illness may play a vital role in determining how much independent behavior is expected or allowed. Environmental factors such as level of access and accommodations that are available to the child to compensate for his or her disability would affect their level of physical independence and may consequently affect other areas of independent behavior. In addition to looking at illness-specific predictor variables, behavioral autonomy variables that are specific to children with a chronic illness could also be examined (i.e., independence with regard to self-management of spina bifida).

Finally, discrepancies between reporters in the same family on measures of adolescent autonomy may be meaningful indicators of various aspects of family functioning. For example, one study found that discrepancies between mother and child report of the child's behavioral autonomy predicted a higher frequency of mother-adolescent conflict. Six months later, however, these same discrepancies were related to subsequent increases in mother-adolescent attachment, suggesting that differing perspectives on who makes the decisions within the family during adolescence may contribute to conflictive, though ultimately adaptive transformations in family relationships. (Holmbeck \& O'Donnell, 1991). Several studies have found that, for children with chronic illness, discrepancies in parent and child reports of decision making autonomy specifically regarding the management of the child's medical regimen (i.e. whether the child or parent is responsible for daily illness management tasks) may be related to higher family conflict, nonadherence, and morbidity (Miller \& Drotar, 2003; Walders, Drotar, \& Kercsmar, 2000). Further research on the nature of discrepancies between family members' reports of trajectory of autonomy development in children with spina bifida may provide a greater understanding of family relationship transformations that may occur over time.

Several clinical implications may be drawn from the current study. Results suggest that social passivity and a lack of self-reliant behavior may be at the heart of the psychosocial difficulties that children with spina bifida face relative to their peers. Targeting these areas during childhood may prevent future more serious social functioning difficulties during adolescence. The divide between children with spina bifida and their peers in the area of behavioral autonomy is already evident in childhood, prior to the transition to adolescence when differences in independent behavior may appear more salient. Therefore, professionals should begin targeting the independent functioning of children with spina bifida early and prior to adolescence. Families should be educated about this important issue and encouraged early on to promote independent behavior in their children. Authoritative parenting, which is characterized by parenting behavior that supports autonomy growth, has been consistently associated with positive psychosocial outcomes (Steinberg, Lamborn, Dornbusch, \& Darling, 1992; 
Steinberg, Mounts, Lamborn, \& Dornbusch, 1991), and increased opportunities for decision making within the family have been linked with increased positive self-esteem and ego development (Eccles et al., 1993; Allen, Hauser, Bell, \& O’Connor, 1994). Families may promote independent behavior by encouraging active exploration of the environment, eliciting the child's opinions, engaging children in active problem solving, and involving children in the process of family decision making.

Children with spina bifida appear to be at greatest risk in the area of behavioral autonomy in the classroom as their level of intrinsic motivation in school is low and does not appear to increase with age. Although children with spina bifida tend to be in mainstream school settings, perhaps providing early interventions within that setting may be essential to increasing opportunities for academic success and promoting greater intrinsic motivation, to mitigate the risk for later academic problems. Specifically, support for autonomy in the middle school environment, such as providing opportunities for choice and for sharing viewpoints in class discussions, had been shown to enhance later academic motivation, as well as school and emotional functioning (Roeser, Eccles, \& Sameroff, 1998). Finally, findings of the current study suggest that some factors may be indicators of increased risk for developmental delays in social functioning for children with spina bifida. In particular, interventions should target boys with spina bifida, as well as both boys and girls with spina bifida who exhibit lower levels of intellectual ability.

In conclusion, the present investigation examined trajectories of growth in emotional and behavioral autonomy, considered to be critical tasks of adolescent development. A developmental perspective was taken by utilizing a longitudinal design to examine change across a significant developmental transition. A family systems approach also informed this study in that multiple informants and perspectives were examined. The current study expanded on the developmental literature concerning behavioral autonomy by comparing trajectories of autonomy development across groups of children with and without a chronic illness. Findings of this study provide evidence that children with spina bifida demonstrate distinct developmental trajectories across the transition to adolescence with regard to growth in autonomy than their healthy peers. More research is warranted to clarify those factors that relate to autonomy growth over time and to extend the current investigation to examine both earlier and later developmental time periods. Additional research in this area may further elucidate the process of adolescent autonomy development and support families of children with chronic illnesses in promoting achievement of this critical developmental competency.

\section{References}

Aiken, L. S., \& West. S. G. (1991). Multiple regression: Testing and interpreting interactions. Thousand Oaks, CA: Sage Publications, Inc.

Allen, J. P., Hauser, S. T., Bell, K. L., \& O'Connor, T. G. (1994). Longitudinal assessment of autonomy and relatedness in adolescentfamily interactions as predictors of adolescent ego development and self-esteem. Child Development, 65, 179-194.

Appleton, P. L., Ellis, N. C., Minchom, P. E., Lawson, V., Boll, V., \& Jones, P. (1997). Depressive symptoms and self-concept in young people with spina bifida. Journal of Pediatric Psychology, 22, 707-722.

Appleton, P. L., Minchon, P. E., Ellis, N. C., Elliot, C. E., Boll, V., \&
Jones, P. (1994). The self concept of young people with spina bifida: A population-based study. Developmental Medicine and Child Neurology, 36, $198-215$.

Blum, R. W., Resnick, M. D., Nelson, R., \& St. Germaine, A. (1991). Family and peer issues among adolescents with spina bifida and cerebral palsy. Pediatrics, $88,280-285$.

Charney, E. B. (1992). Neural tube defects: Spina bifida and myelomeningocele. In M. L. Batshaw \& Y. M. Perret (Eds.), Children with disabilities: A medical primer (3rd ed., pp. 471-488). Baltimore: Paul H. Brookes Publishing.

Coakley, R. M., Holmbeck, G. N., \& Bryant, F. B. (2006). Constructing a prospective model of psychosocial adaptation in young adolescents with spina bifida: An application of optimal data analysis. Journal of Pediatric Psychology, 31, 1084-1099.

Collins, W. A. (1990). Parent-child relationships in the transition to adolescence: Continuity and change in interaction, affect, and cognition. In R. Montemayer, G. Adams, \& T. Gullotta (Eds.), From childhood to adolescence: A transitional period? (Vol. 2; pp. 85-106). Beverly Hills, CA: Sage.

Collins, W. A., Laursen, B., Mortensen, N., Luebker, C., \& Ferreira, M. (1997). Conflict processes and transitions in parent and peer relationships: Implications for autonomy and regulation. Journal of Adolescent Research, 12, 178-198.

Dashiff, C., \& Bartolucci, A. (2002). Autonomy development in adolescents with insulin dependent diabetes mellitus. Journal of Pediatric Nursing, 14, 96-105.

DeLucia, C., \& Pitts, S. C. (2006). Applications of individual growth curve modeling for pediatric psychology research. Journal of Pediatric Psychology, 31, 1002-1023.

Dorner, S. (1976). Adolescents with spina bifida. How they see their situation. Archives of Disease in Childhood, 51, 439-444.

Drotar, D., \& Ievers. (1994). Age differences in parent and child responsibilities for management of cystic fibrosis and insulin-dependent diabetes mellitus. Journal of Developmental and Behavioral Pediatrics, 15, 265-272.

Dunn, L. M., \& Dunn, L. M. (1981). Peabody Picture Vocabulary TestRevised (PPVT). Circle Pines, MN: American Guidance Service.

Eccles, J. S., Midgley, C., Wigfield, A., Buchanan, C. M., Reuman, D., Flanagan, C., et al. (1993). Development during adolescence: The impact of stage-environment fit in young adolescents' experience in schools and in families. American Psychologist, 48, 90-101.

Frank, N. C., Blount, R. L. \& Brown, R. T. (1997). Attributions, coping, and adjustment in children with cancer. Journal of Pediatric Psychology, 22, 563-576.

Friedman, D., Holmbeck, G. N., Jandasek, B., Zukerman, J., \& Abad, M. (2004). Parent functioning in families of preadolescents with spina bifida: Longitudinal implications for child adjustment. Journal of Family Psychology, 18, 609-619.

Fritz, G. K., \& McQuaid, E. L. (2000). Chronic medical conditions: Impact on development. In A. J. Sameroff, M. Lewis, \& S. M. Miller (Eds.), Handbook of Developmental Psychopathology (2nd Ed). New York: Kluwer Academic/Plenum Publishers.

Grotevant, H. D., \& Cooper, C. R. (1985). Patterns of interaction in family relationships and the development of identity exploration in adolescence. Child Development, 56, 415-428.

Hanna, K. M., DiMeglio, L. A., \& Fortenberry, J. D. (2005). Parent and adolescent versions of the diabetes-specific parental support of adolescents' autonomy scale: Development and initial testing. Journal of Pediatric Psychology, 30, 257-271.

Harter, S. (1980). Manual for a scale of intrinsic versus extrinsic orientation in the classroom. Denver, CO: University of Denver.

Hill, J. P., \& Holmbeck, G. N. (1986). Attachment and autonomy during adolescence. In G. J. Whitehurst (Ed.), Annals of child development (Vol. 3; pp. 145-189.) Greenwich, CN: JAI Press. 
Hollingshead, A. A. (1975). Four factor index of social status. Unpublished manuscript, Yale University.

Holmbeck, G. N. (1996). A model of family relational transformations during the transition into adolescence: Parent-adolescent conflict and adaptation. In J. A. Graber, J. Brooks-Gunn, \& A. C. Peterson (Eds.), Transitions through adolescence: Interpersonal domains and context (pp. 167-199). Mahway, NJ: Erlbaum.

Holmbeck, G. N. (1997). Toward terminological, conceptual, and statistical clarity in the study of mediators and moderators: Examples from the child-clinical and pediatric psychology literature. Journal of Consulting and Clinical Psychology, 65, 599-610.

Holmbeck, G. N., Johnson, S. Z., Wills, K. E., McKernon, W., Rose, B., Erklin, S., et al. (2002). Observed and perceived parental overprotection in relation to psychosocial adjustment in preadolescents with a physical disability: The mediational role of behavioral autonomy. Journal of Consulting and Clinical Psychology, 70, 96-110.

Holmbeck, G. N., \& O'Donnell, K. (1991). Discrepancies between perceptions of decision making and behavioral autonomy. New Directions for Child Development, 51, 51-69.

Holmbeck, G. N., Paikoff, R. L., \& Brooks-Gunn, J. (1995). Parenting adolescents. In M. H. Bornstein (Ed.), Handbook of parenting (Vol. 1, pp. 91-118). Mahway, NJ: Erlbaum.

Holmbeck, G. N., Westhoven, V. C., Phillips W.S., Bowers, R., Gruse, C., Nikolopoulos, T., et al. (2003). A multimethod, multi-informant, and multidimensional perspective on psychosocial adjustment in preadolescents with spina bifida. Journal of Consulting and Clinical Psychology, 71, 782-796.

Howe, G. W., Feinstein, C. Reiss, D. Molock, S., \& Berger, K. (1993). Adolescent adjustment to chronic physical disorders: I. comparing neurological and non-neurological conditions. Journal of Child Psychology and Psychiatry, 34, 1153-1171.

Johnson, S. Z., \& Holmbeck, G. N. (1994). Manual for overprotectiveness coding system. Unpublished manual, Loyola University Chicago.

Kwok, O., Underhill, A. T., Berry, J. W., Luo, W., Elliot, T. R., \& Yoon, M. (2008). Analyzing longitudinal data with multilevel models: An example with individuals living with lower extremity intra-articular fractures. Rehabilitation Psychology, 53, 370-386.

Lamborn, S., \& Steinberg, L. (1993). Emotional autonomy redux: Revisiting Ryan and Lynch. Child Development, 64, 483-499.

Lary, J. M., \& Edmonds, L. D. (1996). Prevalence of spina bifida at birth - United States, 1983-1990: A comparison of two surveillance systems. Centers for Disease Control: Morbidity and Mortality Weekly Report, 45, 15-26.

Lavigne, J. V., \& Faier-Routman, J. (1992). Psychological adjustment to pediatric physical disorders: A meta-analytic review. Journal of Pediatric Psychology, 17, 133-157.

Lerner, R. M., \& Galambos, N. L. (1998). Adolescent development: Challenges and opportunities for research, programs, and policies. Annual Review of Psychology, 49, 413-446.

Masten, A. S., Burt, K. B., Roisman, G. I., Obradovic, J., Long, J. D., \& Tellegen, A. (2004). Resources and resilience in the transition to adulthood: Continuity and change. Development and psychopathology, 16, 1071-1094.

McLone, D. G., \& Ito, J. (1998). An introduction to spina bifida. Chicago: Children's Memorial Hospital MM Team.

Miller, V. A., \& Drotar, D. (2003). Discrepancies between mother and adolescent perceptions of diabetes-related decision-making autonomy and their relationship to diabetes-related conflict and adherence to treatment. Journal of Pediatric Psychology, 28, 265-274.

Monsen, R. B. (1992). Autonomy, coping, and self-care agency in healthy adolescents and in adolescents with spina bifida. Journal of Pediatric Nursing, 7, 9-13.

Palmer, D. L., Berg, C. A., Wiebe, D. J., Beveridge, R. M., Korbel, C. D., Upchurch, R., et al. (2004). The role of autonomy and pubertal status in understanding age differences in maternal involvement in diabetes responsibility across adolescence. Journal of Pediatric Psychology, 29, 35-46.
Phares, V., Fields, S., Kamboukos, D., \& Lopez, E. (2005). Still looking for poppa. American Psychologist, 60, 735-736.

Quittner, A. L., \& DiGirolamo, A. M. (1998). Family adaptation to childhood disability and illness. In Ammerman \& Campo (Eds.), Handbook of pediatric psychology and psychiatry (Vol. 2, pp. 70-80). Boston: Allyn and Bacon.

Robin, A. L., \& Foster, S. L. (1989). Negotiating parent-adolescent conflict: A behavioral family systems approach. New York: Guilford.

Roeser, R. W., Eccles, J. S., \& Sameroff, A. J. (1998). Academic and emotional functioning in early adolescence: Longitudinal relations, patterns, and prediction by experience in middle school. Development and Psychopathology, 10, 321-352.

Sattler, J. M. (2002). Assessment of children: Behavioral and clinical applications. (4th ed.) San Diego: Jerome M. Sattler Publisher, Inc.

Shaw, R. J. (2001). Treatment adherence in adolescents: Development and psychopathology. Clinical Child Psychology and Psychiatry, 6, 137-150.

Sigafoos, A. D., Feinstein, C. B., Damond, M., \& Reiss, D. (1988). The measurement of behavioral autonomy in adolescence: The Autonomous functioning checklist. In S. C. Feinstein \& A. H. Esman (Eds.), Adolescent psychiatry: Developmental and clinical studies, vol. 15. Annals of the American Society for Adolescent Psychiatry. (pp. 432-462). Chicago, IL: University of Chicago.

Silverberg, S. B., \& Gondoli, D. M. (1996). Autonomy in adolescence: A contextualized perspective. In G. R. Adams, R. Montemayer \& T. P. Gullotta (Eds.), Psychosocial development during adolescence (pp. 1261). Thousand Oaks, CA: Sage.

Singer, J. D. (1998). Using SAS PROC MIXED to fit multilevel models, hierarchical models, and individual growth models. Journal of Educational and Behavioral Statistics, 24, 323-355.

Smetana, J. G., Yau, J., Restrepo, A., \& Braeges, J. L. (1991). Adolescentparent conflict in married and divorced families. Developmental Psychology, 27, 1000-1010.

Snijders, T. A. B., \& Bosker, R. J. (1999). Multilevel analysis: An introduction to basic and advanced multilevel modeling. London: Sage.

Steinberg, L. (1987). Impact of puberty on family relations: Effects of pubertal status and pubertal timing. Developmental Psychology, 23, 451-460.

Steinberg, L., Lamborn, S. D., Dornbusch, S. M., \& Darling, N. (1992). Impact of parenting practices on adolescent achievement: Authoritative parenting, school involvement, and encouragement to succeed. Child Development, 63, 1266-1281.

Steinberg, L., \& Morris, A. S. (2001). Adolescent development. Annual Review of Psychology, 52, 83-110.

Steinberg, L., Mounts, N. S., Lamborn, S. D., \& Dornbusch, S. M. (1991). Authoritative parenting and adolescent adjustment across varied ecological niches. Journal of Research on Adolescence, 1, 19-36.

Steinberg, L., \& Silverberg, S. B. (1986). The vicissitudes of autonomy during early adolescence. Child Development, 57, 841-851.

Taylor, D. (1985). Developmental rate is the major differentiator between the sexes. Behavior and Brain Sciences, 8, 459-460.

Walders, N., Drotar, D., \& Kercsmar, C. (2000). The allocation of family responsibility for asthma management tasks in African-American adolescents. Journal of Asthma, 37, 89-99.

Williams, P. G., Holmbeck, G. N., \& Neff Greenley, R. (2002). Adolescent health psychology. Journal of Consulting and Clinical Psychology, 70, $828-842$.

Wills, K. E. (1993). Neuropsychological functioning in children with spina bifida and/or hydrocephalus. Journal of Clinical Child Psychology, 22, 247-265.

Wills, K. E., Holmbeck, G. N., Dillon, K., \& McLone, D. G. (1990). Intelligence and achievement in children with myelomeningocele. Journal of Pediatric Psychology, 15, 161-176.

Received June 19, 2008 Revision received September 10, 2008 Accepted September 20, 2008 